\title{
Quantitative aspects of electrocardiograms of adults in a Jamaican rural population ${ }^{1}$
}

\author{
L. Ruiz, ${ }^{2}$ W. E. Miall, ${ }^{3}$ and A. V. Swan ${ }^{4}$ \\ From 1 Medical Research Council's Epidemiology Unit (Famaica), University of West Indies, Kingston 7, \\ famaica
}

The values of selected measurements from scalar electrocardiograms of a representative famaican population are reported. The tracings were obtained from 1067 adults aged 35 to 64 years, just under 90 per cent of 1200 men and women selected randomly from a defined community of a hilly inland rural area. The participants were mostly small farmers and their womenfolk, and they were of African origin.

Measurements included intervals, axes, and amplitudes and three indices of left heart involvement - Morris's index of left atrial disease, Estes' score for left ventricular hypertrophy, and the Sokolow-Lyon criteria. Their distributions are compared with data from similar epidemiological studies and provide values for an ethnic group for which there are few population-based reports.

The striking feature of these tracings was the high proportion with evidence of left ventricular hypertrophy, particularly among those of men. The relation between certain electrocardiographic characteristics and age, body build, arterial pressure, and heart rate was investigated by multiple regression analysis, and this showed that little of the variation of most electrocardiographic measurements was explained by these variables.

The growth of cardiovascular epidemiology has resulted in a greater use of electrocardiographic examinations of samples of the general population in different parts of the world, but few attempts have been made to relate the electrocardiographic and other physical characteristics of those examined. A detailed study of factors influencing electrocardiographic measurements within a population may lead to better understanding of differences between individuals in that community and of differences between the electrocardiographic characteristics of that and other populations.

Received 5 February 1973.

1 This study was supported by the Medical Research Council and Ministry of Overseas Development and by a grant from the World Health Organisation.

2 Formerly W.H.O. Fellow. Present address: Universidad Peruana 'Cayetano Heredia', Instituto de Investigaciones de la Altura, Laboratorio Cardiovascular, Apartado 6083, Lima, Peru.

${ }^{3}$ Formerly Director, Medical Research Council's Epidemiology Unit (Jamaica), University of the West Indies, Kingston 7, Jamaica. Present address: M.R.C./D.H.S.S. Epidemiology and Medical Care Unit, Northwick Park Hospital, Watford Road, Harrow, Middlesex HAI 3UJ.

${ }^{4}$ Formerly Statistician, Medical Council's Epidemiology Unit (Jamaica), University of the West Indies, Kingston 7, Jamaica. Present address: Department of Clinical Epidemiology and Social Medicine, St. Thomas's Hospital Medical School, London S.E.I 7 EH.
An unexpectedly high prevalence of abnormalities in a representative rural community in Jamaica included unusually high rates for tall $R$ waves in left ventricular leads and for ST segment and $T$ wave changes (Miall et al., 1972a). There is evidence suggesting that ethnic differences in QRS amplitudes exist, but when increases in QRS area are accompanied by secondary changes in the ventricular repolarization process they are usually taken to indicate cardiac pathology.

Since among clinical conditions imposing a flow or pressure overload on the left ventricle only hypertension was common in this community, it seemed reasonable to assume that if $Q R S$ and $T$ wave changes corresponded mainly with different stages of hypertensive heart disease, the amplitudes of these items would relate closely with blood pressure measurements if other interfering variables such as age, sex, and body build were also taken into account.

In this paper we report the values of selected measurements from the scalar electrocardiograms of the same Jamaican population and examine, by multivariate analysis, their relation with age, body build, arterial pressure, and heart rate in the two sexes. 
TABLE I Population samples: Lawrence Tavern, famaica, 1962-63

\begin{tabular}{llllll}
\hline & $\begin{array}{l}\text { Age } \\
(y r)\end{array}$ & $\begin{array}{l}\text { Total population } \\
\text { at census }\end{array}$ & $\begin{array}{l}\text { Random } \\
\text { samples }\end{array}$ & Examined & $\begin{array}{l}\text { Response } \\
\text { rate (\%) }\end{array}$ \\
\hline Men & $35-44$ & 371 & 200 & 168 & $84 \cdot 0$ \\
& $45-54$ & 323 & 200 & 180 & $90 \cdot 0$ \\
& $55-64$ & 270 & 200 & 178 & $89 \cdot 0$ \\
\hline \multirow{2}{*}{ Women } & Total & 964 & 600 & 526 & $87 \cdot 7$ \\
& $35-44$ & 274 & 200 & 181 & $90 \cdot 5$ \\
& $45-54$ & 284 & 200 & 181 & $90 \cdot 5$ \\
& $55-64$ & 262 & 200 & 179 & $89 \cdot 5$ \\
\hline & Total & 820 & 600 & 541 & $90 \cdot 2$ \\
\hline
\end{tabular}

\section{Population sample}

The population inhabiting a hilly inland rural area surrounding the village of Lawrence Tavern, 15 miles from Jamaica's capital, Kingston, was defined by private census in 1962. Stratified random samples of the adult population, together including 200 subjects of each sex in each of the three decades from 35 to 64 years, were selected, and each person was asked to attend a centre where cardiovascular investigations were carried out in 1962 and $1963.1067(88.9 \%)$ of the 1200 people co-operated. Table I shows the response rates, by age and sex.

This community of subsistence farmers and their families has been described in detail elsewhere (Miall

TABLE 2 Some electrocardiographic characteristics by age and sex, Lawrence Tavern, famaica

\begin{tabular}{|c|c|c|c|c|c|c|c|c|c|c|}
\hline \multirow[t]{3}{*}{ Electrocardiograms } & \multicolumn{6}{|c|}{ Men, age (yr) } & \multirow{2}{*}{\multicolumn{2}{|c|}{ Total $(n=526)$}} & \multirow{2}{*}{\multicolumn{2}{|c|}{$\begin{array}{l}\text { Women, age }(y r) \\
35-44(n=I 8 I)\end{array}$}} \\
\hline & \multicolumn{2}{|c|}{$35-44(n=168)$} & \multicolumn{2}{|c|}{$45-54(n=180)$} & \multicolumn{2}{|c|}{$55-64(n=178)$} & & & & \\
\hline & Mean & $S D$ & Mean & $S D$ & Mean & $S D$ & Mean & $S D$ & Mean & $S D$ \\
\hline Heart rate (beats/min) & $72 \cdot 6$ & $12 \cdot 3$ & $71 \cdot 4$ & 14.4 & $72 \cdot 0$ & $13 \cdot 7$ & $72 \cdot 0$ & 13.5 & $83 \cdot 3$ & $I \cdot 50$ \\
\hline $\begin{array}{l}\text { Intervals } \\
\text { PR (msec) } \\
\text { QRS (msec) } \\
\text { Intrinsicoid deflection (msec) } \\
\text { QTC (msec) } \\
\text { QT ratio }\end{array}$ & $\begin{array}{r}169 \\
81 \\
34 \\
387 \\
0.968\end{array}$ & $\begin{array}{l}28 \\
8 \\
6 \\
22 \\
0.055\end{array}$ & $\begin{array}{l}171 \\
81 \\
34 \\
389 \\
0.974\end{array}$ & $\begin{array}{c}25 \\
9 \\
6 \\
23 \\
0.058\end{array}$ & $\begin{array}{r}167 \\
82 \\
34 \\
400 \\
I \cdot 000\end{array}$ & $\begin{array}{l}26 \\
15 \\
7 \\
28 \\
0.071\end{array}$ & $\begin{array}{l}169 \\
81 \\
34 \\
392 \\
0.981\end{array}$ & $\begin{array}{l}26 \\
11 \\
7 \\
25 \\
0.063\end{array}$ & $\begin{array}{r}165 \\
81 \\
32 \\
404 \\
1 \cdot 010\end{array}$ & $\begin{array}{l}23 \\
7 \\
6 \\
21 \\
0.052\end{array}$ \\
\hline $\begin{array}{l}\text { Mean frontal axis (degrees) } \\
\text { P } \\
\text { QRS } \\
\text { T }\end{array}$ & $\begin{array}{l}56 \cdot 2 \\
51 \cdot 2 \\
36 \cdot 5\end{array}$ & $\begin{array}{l}15 \cdot 0 \\
26 \cdot 1 \\
24 \cdot 6\end{array}$ & $\begin{array}{l}57 \cdot 7 \\
38 \cdot 9 \\
36 \cdot 9\end{array}$ & $\begin{array}{l}11 \cdot 3 \\
33 \cdot 2 \\
23 \cdot 5\end{array}$ & $\begin{array}{l}56 \cdot 7 \\
37 \cdot 3 \\
37 \cdot 7\end{array}$ & $\begin{array}{l}19 \cdot 8 \\
32 \cdot 7 \\
39 \cdot 8\end{array}$ & $\begin{array}{l}56 \cdot 9 \\
42 \cdot 3 \\
37 \cdot 1\end{array}$ & $\begin{array}{l}15 \cdot 8 \\
31 \cdot 4 \\
30 \cdot 3\end{array}$ & $\begin{array}{l}54 \cdot 2 \\
38 \cdot 9 \\
30 \cdot 3\end{array}$ & $\begin{array}{l}13 \cdot 0 \\
24 \cdot 1 \\
18 \cdot 1\end{array}$ \\
\hline $\begin{array}{l}\text { Amplitudes of selected waves }(\mathrm{mm}) \\
\text { aVL-R } \\
\text { VI-R } \\
-\mathrm{S} \\
\mathrm{V}_{5}-\mathbf{R} \\
-\mathrm{S} \\
-\mathrm{T} \\
\mathrm{V} 6-\mathbf{R} \\
-\mathrm{T}\end{array}$ & $\begin{array}{r}3 \cdot 1 \\
3 \cdot 0 \\
12 \cdot 5 \\
21 \cdot 2 \\
2 \cdot 0 \\
4 \cdot 7 \\
17 \cdot 1 \\
3 \cdot 5\end{array}$ & $\begin{array}{l}2 \cdot 7 \\
2 \cdot 5 \\
5 \cdot 3 \\
8 \cdot 5 \\
2 \cdot 7 \\
2 \cdot 7 \\
6 \cdot 8 \\
2 \cdot 2\end{array}$ & $\begin{array}{r}4 \cdot 0 \\
2 \cdot 2 \\
11 \cdot 4 \\
21 \cdot 1 \\
1 \cdot 8 \\
4 \cdot 7 \\
16 \cdot 7 \\
3.5\end{array}$ & $\begin{array}{l}3 \cdot 5 \\
1 \cdot 9 \\
5 \cdot 6 \\
8 \cdot 1 \\
2 \cdot 7 \\
2 \cdot 6 \\
6.5 \\
2 \cdot 0\end{array}$ & $\begin{array}{r}4 \cdot 1 \\
2 \cdot 8 \\
12 \cdot 2 \\
21 \cdot 3 \\
2 \cdot 3 \\
4 \cdot 0 \\
16 \cdot 5 \\
2 \cdot 9\end{array}$ & $\begin{array}{l}3.5 \\
2.9 \\
7.7 \\
8.9 \\
3.4 \\
3.2 \\
6.8 \\
2.2\end{array}$ & $\begin{array}{r}3.8 \\
2.6 \\
12.0 \\
21 \cdot 2 \\
2.0 \\
4.4 \\
16.8 \\
3.3\end{array}$ & $\begin{array}{l}3 \cdot 3 \\
2 \cdot 4 \\
6 \cdot 3 \\
8 \cdot 5 \\
3 \cdot 0 \\
2 \cdot 9 \\
6 \cdot 7 \\
2 \cdot 2\end{array}$ & $\begin{array}{r}4 \cdot 3 \\
2 \cdot 0 \\
10 \cdot 6 \\
15 \cdot 3 \\
1 \cdot 0 \\
2 \cdot 7 \\
13 \cdot 0 \\
2 \cdot 2\end{array}$ & $\begin{array}{l}3 \cdot 2 \\
1 \cdot 5 \\
4 \cdot 6 \\
5 \cdot 6 \\
1 \cdot 8 \\
1 \cdot 3 \\
4 \cdot 2 \\
1 \cdot 0\end{array}$ \\
\hline $\begin{array}{l}\text { Indexes of left heart preponderance } \\
\mathbf{P}-\text { terminal force, VI } \\
\text { (Morris's index) } \\
\text { S-VI }+\mathrm{R}-\mathrm{V}_{5} \text { or V6 } \\
\text { (Sokolow-Lyon's index) } \\
\text { Estes' score }\end{array}$ & $\begin{array}{c}-0.005 \\
33.8 \\
1.8\end{array}$ & $\begin{array}{r}0.016 \\
\text { II.2 } \\
1 \cdot 7\end{array}$ & $\begin{array}{c}-0.009 \\
32 \cdot 6 \\
1.8\end{array}$ & $\begin{array}{r}10.9 \\
1.8\end{array}$ & $\begin{array}{c}-0.014 \\
33.7 \\
2.0\end{array}$ & $\begin{array}{c}0.023 \\
12 \cdot 8 \\
2 \cdot 1\end{array}$ & $\begin{array}{r}-0.010 \\
33.4 \\
1.9\end{array}$ & $\begin{array}{r}\text { II } \cdot 7 \\
\text { I.9 }\end{array}$ & $\begin{array}{c}-0.003 \\
26 \cdot 1 \\
0.8\end{array}$ & $\begin{array}{l}0.011 \\
8 \cdot 2 \\
1 \cdot 2\end{array}$ \\
\hline
\end{tabular}


et al., 1972a). Ethnically they are of predominantly African origin with varying degrees of admixture with European, Indian, and Chinese blood. The great majority are smallholders growing a variety of fruit and vegetable crops on hillsides which are much too steep for mechanical cultivation.

\section{Methods and techniques}

Twelve-lead electrocardiograms were recorded on one of two direct writing single-channel instruments at a paper speed of $25 \mathrm{~mm}$ per second. The intake of food and tobacco before the examination was not restricted but nearly all tracings were taken in the morning before the main meal of the day. Arterial pressure measurements, obtained on the right arm in subjects who had been seated for at least 10 minutes, were made using a shifting-zero sphygmomanometer (Wright and Dore, 1970). Height and weight (in light clothing) were also recorded.

For each electrocardiographic tracing one observer (L.R.) recorded the heart rate, the $P R$ interval, $Q R S$ duration, the QT interval and the intrinsicoid deflection

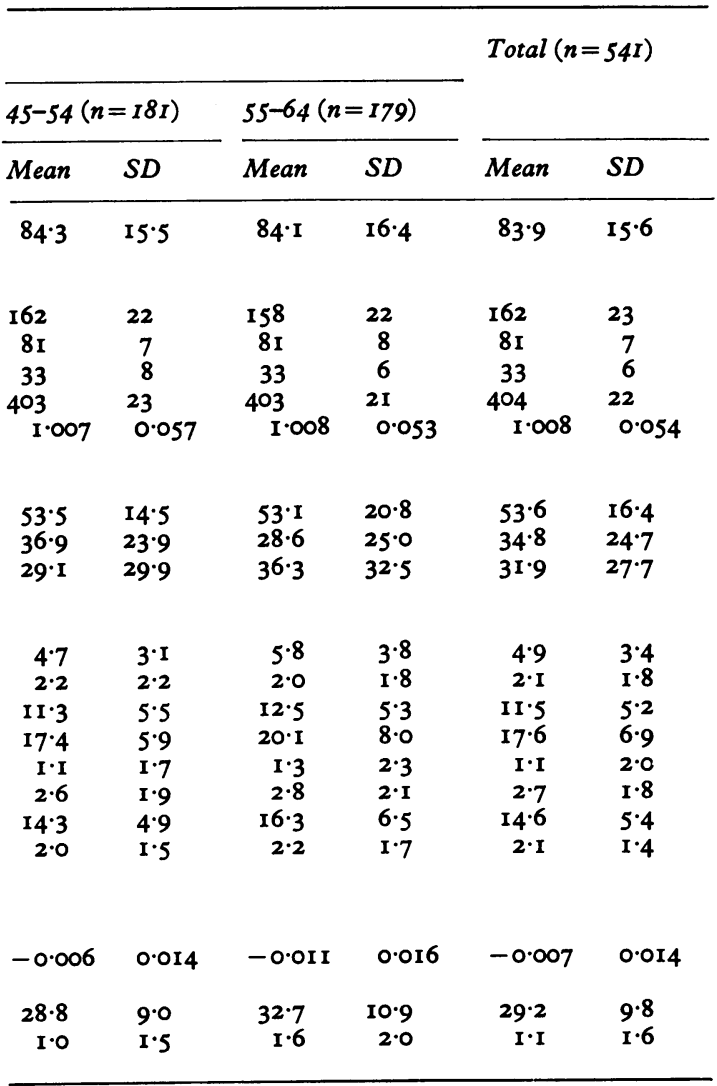

time in $\mathrm{V}_{5}$ or V6. The mean electrical axis of $\mathrm{P}, \mathrm{QRS}$, and $T$ in the frontal plane and the position of the electrical transition zone on the chest were noted. Wave amplitudes of $R$ in aVL, $R$ and $S$ in $V_{I}, R, S$, and $T$ in $V_{5}$, and $R$ and $T$ in V6 were measured. Finally the $P$ terminal force in VI - Morris's index (Morris et al., 1964) - and the score for left ventricular hypertrophy proposed by Estes (Estes, 1966) were calculated.

The measurement of electrocardiographic intervals (to the nearest $0.01 \mathrm{sec}$ ) and amplitudes (to the nearest $0.25 \mathrm{~mm}$ ) followed the lines recommended by the Committee on Electrocardiography of the American Heart Association (1967). For convenience the PR and QT intervals were measured in lead II in all cases. Heart rate was also recorded in the same lead to simplify the calculation of the corrected QT interval and the QT ratio. Mean electrical axes were determined by using the hexa-axial reference system. The use of a magnifying device (designed by G. A. Rose and D. D. Reid) and a plastic scale facilitated measurements. Data were transferred to punch cards and analysed on an IBM 360 computer.

\section{Results}

\section{(I) Age and sex trends in electrocardiographic} measurements

Means and standard deviations of all measurements are shown for men and women, by age, in Table 2.

(a) Heart rate In both sexes the mean heart rate showed little change with increase in age. Heart rate averaged II to 12 beats per minute slower in men than in women, a difference that was significant $(P<0.001)$ in all age groups and was reflected by corresponding differences at the extremes of the distribution where 2.3 per cent of men but no women had heart rates below 50, and 3.7 per cent of women but only 0.6 per cent of men had rates over 120 beats a minute.

(b) Intervals PR intervals were correspondingly greater in men than women though the PR interval was fractionally longer in men than in women after adjusting for heart rate. At ages over 45 the sex difference in the $P R$ interval was significant $(P<0.001)$. QRS durations and the intrinsicoid áflection time showed little difference in mean values between the sexes, and no trends with age. Abnormal values for $Q R S$ duration (those exceeding $0.12 \mathrm{sec})$ were detected in $8 \mathrm{men}(\mathrm{I} .5 \%)$ but only I woman $(0.2 \%)$, and abnormal values for the intrinsicoid deflection time (those exceeding $0.045 \mathrm{sec}$ ) were present in 7.2 per cent of men and 4.1 per cent of women.

The QT interval, corrected for heart rate, and the QT ratio were both fractionally greater in 
women than in men, and in men - but not in women - showed an increase with age.

(c) Mean electrical axes in frontal plane The direction of atrial activation, the $P$ axis, was slightly greater in men than in women but only significantly so in the 45 to 54 group $(P<0.01)$, and showed little trend with age in either sex. The mean axis of QRS, on the other hand, shifted to the left with increasing age, in both sexes. Left axis deviation of $-30^{\circ}$ or more was present in 3.8 per cent of men and 1.5 per cent of women. Right axis deviation of $+120^{\circ}$ or more was only detected in 4 men, 2 of whom had right bundle-branch block, and in no women. The somewhat greater mean values of $P$ axis and $Q R S$ axis in men than women probably indicate a more vertical heart position, pulmonary causes of right atrial or right ventricular hypertrophy being very rare in this population.

The mean values of the $T$ axis were also somewhat larger in men than women - significantly so $(\mathbf{P}<0.01)$ in the two younger age groups; the mean values remained constant with age but their variance increased because the $T$ axis may shift in either direction. This contrasts with the QRS axis which rarely deviates to the right in this population.

(d) Wave amplitudes The amplitude of $R$ in aVL increased with age in both sexes, and was significantly greater in women than in men in each of the three age groups $(P<0.001,<0.05,<0.001)$. Values exceeding $12 \mathrm{~mm}$ were present in 5.0 per cent of women and 2.9 per cent of men. These differences in aVL voltage accord with the differences in QRS axis already mentioned.

The amplitudes of the $R$ wave in leads $V_{5}$ and V6 were greater in men than in women, and in men did not show the increase with age which was present in women. High amplitude $\mathbf{R}$ waves are one of the most striking characteristics of these electrocardiograms, and 3.0 per cent of men and $I \cdot I$ per cent of women had values of $R$ in $V_{5}$ exceeding $40 \mathrm{~mm}$. The values of $S$ in VI followed those of $R$ in $V_{5}$ and V6.

The mean amplitudes of $\mathrm{T}$ in $\mathrm{V}_{5}$ and $\mathrm{V} 6$ tended to decline with increase in age, but were consistently and significantly $(P<0.001)$ smaller in women than in men.

(e) Indices of left heart preponderance. The assessment of left ventricular hypertrophy on the basis of amplitude criteria alone lacks specificity, and to assess the extent of left heart involvement Morris's index, the Sokolow-Lyon criteria, and Estes' score have been calculated.

Morris's index of impaired atrial $P$ wave activation is derived from the product of the width (in seconds) and the depth (in $\mathrm{mm}$ ) of the terminal part of $P$ in VI (Morris et al., 1964). It is considered abnormal if its negative value exceeds $-0.03 \mathrm{~mm}$ sec. The mean value of this index increased in negativity with age in both sexes and was consistently greater in men than in women, 8.2 per cent of men and 5.0 per cent of women having abnormal values.

The Sokolow-Lyon criteria - the sum of S in VI and $\mathrm{R}$ in $\mathrm{V}_{5}$ or V6, whichever is the greater (Sokolow and Lyon, 1949) - had mean values that were high in both sexes but consistently higher in men, and accorded with the other amplitude findings already described.

Estes' score, which is based on QRS amplitudes, axis deviation, $Q R S$ duration and intrinsicoid deflection time, and ST depression, is considered to indicate probable left ventricular hypertrophy at a score of 4 , and definite left ventricular hypertrophy at a score of 5 or greater (Estes, 1966). The mean values again showed no age trend in men but a clear-cut

TABLE 3 Means and standard deviations of blood pressure and Quetelet's index by age and sex, Lawrence Tavern, famaica

\begin{tabular}{|c|c|c|c|c|c|c|c|c|}
\hline & \multirow[t]{2}{*}{$A g e(y r)$} & \multirow[t]{2}{*}{ No. } & \multicolumn{2}{|c|}{$\begin{array}{l}\text { Systolic blood } \\
\text { pressure }(\mathrm{mmHg})\end{array}$} & \multicolumn{2}{|c|}{$\begin{array}{l}\text { Diastolic blood } \\
\text { pressure }(\mathrm{mmHg})\end{array}$} & \multicolumn{2}{|c|}{$W / H^{2} \times 100^{\star}$} \\
\hline & & & Mean & $S D$ & Mean & $S D$ & Mean & $S D$ \\
\hline Men & $\left\{\begin{array}{l}35-44 \\
45-54 \\
55-64\end{array}\right.$ & $\begin{array}{l}168 \\
180 \\
178\end{array}$ & $\begin{array}{l}128 \cdot 3 \\
134 \cdot 5 \\
142 \cdot 3\end{array}$ & $\begin{array}{l}18 \cdot 4 \\
22 \cdot 5 \\
27 \cdot 8\end{array}$ & $\begin{array}{l}80.6 \\
84.4 \\
85.5\end{array}$ & $\begin{array}{l}12.8 \\
13.5 \\
14.8\end{array}$ & $\begin{array}{l}3 \cdot 21 \\
3 \cdot 20 \\
3 \cdot 10\end{array}$ & $\begin{array}{l}0.35 \\
0.33 \\
0.31\end{array}$ \\
\hline Women & $\left\{\begin{array}{l}35-44 \\
45-54 \\
55-64\end{array}\right.$ & $\begin{array}{l}181 \\
181 \\
179\end{array}$ & $\begin{array}{l}127.9 \\
145.3 \\
156.5\end{array}$ & $\begin{array}{l}20 \cdot 1 \\
29 \cdot 0 \\
28 \cdot 7\end{array}$ & $\begin{array}{l}82 \cdot 7 \\
90 \cdot 1 \\
9 I \cdot I\end{array}$ & $\begin{array}{l}12.4 \\
15.9 \\
15.8\end{array}$ & $\begin{array}{l}3 \cdot 48 \\
3 \cdot 47 \\
3 \cdot 27\end{array}$ & $\begin{array}{l}0.62 \\
0.72 \\
0.55\end{array}$ \\
\hline
\end{tabular}

* Weight $(\mathrm{lb}) / \mathrm{ht}^{2}$ (inches) $\times 100$ (Quetelet's index) 
increase with age in women, the mean values in the younger two age groups being significantly greater in men $(\mathrm{P}<0.001)$. 13.3 per cent of men and 6.8 per cent of women showed probable left ventricular hypertrophy, and 6.8 per cent of men and 3.9 per cent of women showed definite left ventricular hypertrophy using this scoring system which is perhaps the most specific of the various means of assessing left ventricular hypertrophy electrocardiographically.

These three indices of left heart involvement, and their associations with symptoms, other physical characteristics, and prognosis are discussed more fully elsewhere (Ruiz, Miall, and Swan, 1973).

(2) Interrelation between age, body build, arterial pressure, and heart rate

Mean values of systolic and diastolic pressure increase in successive age groups in both sexes whereas Quetelet's index (wt in $\mathrm{lb} / \mathrm{ht}^{2}$ in inches, $\times 100$ ) tends to decrease with age (Table 3 ). Simple correlation coefficients between age, Quetelet's index, systolic and diastolic pressure, and heart rate, and between these variables and PR interval, $Q R S$ and $T$ axes, and the amplitudes or $R$ in aVL, $S$ in VI, $R$ and $T$ in $V_{5}$ were calculated (and are available on request from the authors).

A negative correlation between age and Quetelet's index of body build was significant (at the $\mathrm{I} \%$ level) in both sexes, but small. Older subjects were rela- tively lighter than younger ones. Systolic and diastolic pressure were highly correlated $(+0.80)$ in both sexes. Arterial pressure was significantly and positively associated with heavier body build in men, but not in women, and with heart rate in both sexes.

(3) Relation between selected electrocardiographic characteristics and age, body build, arterial pressure, and heart rate

The relation between age, body build, systolic pressure, diastolic pressure, and heart rate and the following seven electrocardiographic measurements: $\mathrm{PR}$ interval, $\mathrm{QRS}$ and $\mathrm{T}$ axes, and the amplitudes of $R$ in aVL, of $S$ in VI, and of $R$ and $T$ in $V_{5}$, was determined by multiple regression analysis. The regression equations are shown in Table 4, with the significance of the coefficients and the proportion of the total variation of each electrocardiographic measurement which is explained by the combined influence of these 5 variables.

PR interval The regression coefficients of PR interval on systolic pressure and heart rate in men, and on age and heart rate in women are statistically significant, the greater the systolic pressure in men and the greater the age in women and, of course, the greater the heart rate in both sexes the shorter the PR interval. PR interval is, however, largely independent of the 5 variables considered which

TABLE 4 Multiple regression of certain electrocardiographic measurements on age, body build, arterial pressure and heart rate, Lawrence Tavern, Jamaica

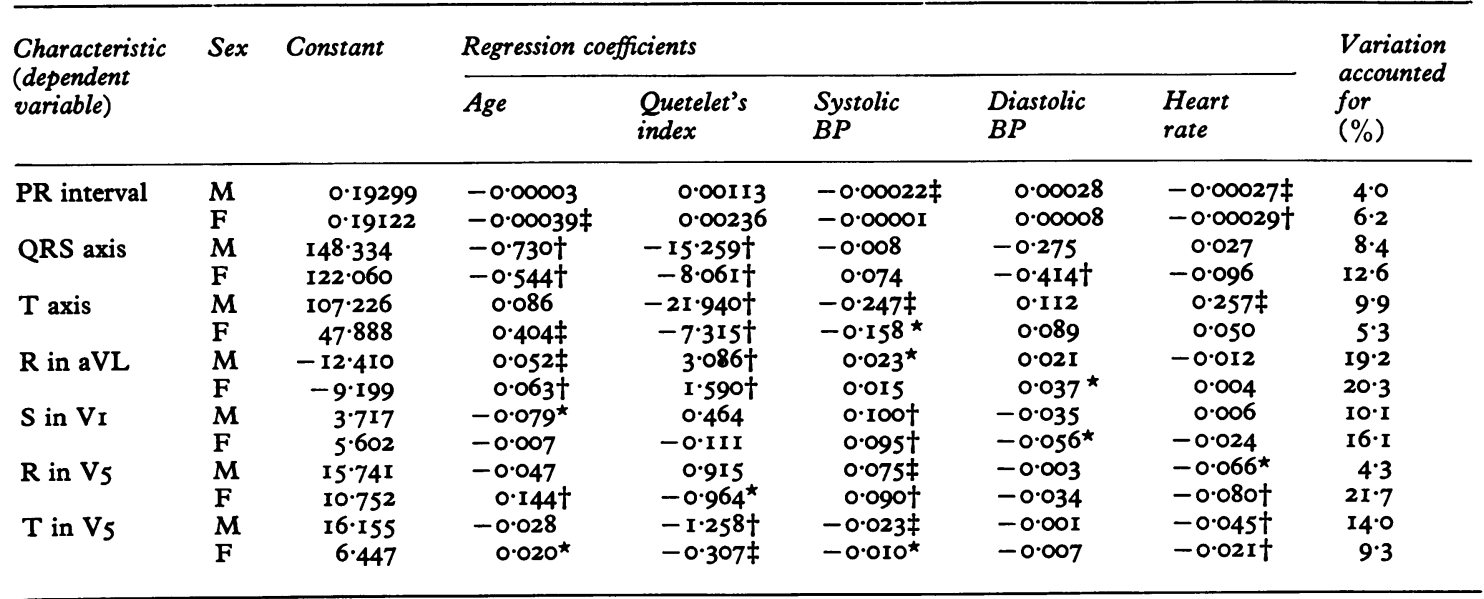

$\mathrm{M}=$ Men 35 to 64 years, $\mathrm{n}=518$.

$\mathrm{F}=$ Women 35 to 64 years, $\mathrm{n}=533$.
* Significant at $5 \%$ level.

¥ Significant at $\mathrm{I} \%$ level.

+ Significant at $0.1 \%$ level. 
together account for only 4 per cent of its variation in men and 6 per cent in women.

QRS axis $Q R S$ axis is highly significantly related to age and to Quetelet's index in both sexes, greater age and heavier body build being associated with a shift to the left. Diastolic pressure in women has a significant influence on QRS axis in the same direction but the coefficients on arterial pressure are otherwise insignificant. This is because their influences are shared between the two pressures; if the influence of systolic pressure is considered, omitting that of diastolic pressure, or conversely if the influence of diastolic pressure is considered separately from that of systolic, an increase in either pressure is associated with a significant shift to the left of QRS axis. Pulse pressure, however, is not significantly related with QRS axis. Eight per cent of the total variation of $Q R S$ axis in men and 13 per cent in women are explained by the five variables considered.

T axis $T$ axis is significantly influenced by body build and systolic pressure in both sexes, increases in either being associated with a shift to the left. Increase of heart rate in men, and age in women, are each significantly associated with a shift of $\mathrm{T}$ axis to the right. The opposite signs of the coefficients on systolic and diastolic pressure suggested a possible influence of pulse pressure and this was highly significantly associated with $\mathrm{T}$ axis shift (to the left) in both sexes. Only Io per cent of the total variation in $\mathrm{T}$ axis in men, and 5 per cent in women, are explained by these 5 variables.

$R$ in aVL The amplitude of $R$ in aVL increases significantly with age, and with body build, in both sexes when the influence of other variables is held constant. In both sexes the separate influences of either systolic or diastolic pressure are significant and positive, but considered together systolic pressure takes a significant share in men and diastolic pressure in women. Heart rate has no significant association with the amplitude of $R$ in aVL in either sex. The 5 variables together explain 19 per cent of its variation in men and 20 per cent in women.

$\mathbf{S}$ in VI In both sexes increased systolic pressure is associated with an increase in amplitude of $S$ in VI. Again, the opposite signs of the pressure coefficients suggest a possible role of pulse pressure and the substitution of pulse pressure for both systolic and diastolic pressure gave positive coefficients which were highly significant $(<0.00 \mathrm{I})$. S in VI decreases with age when the other variables are held constant, significantly only in men. Together the 5 variables account for Io per cent of its variation in men and 16 per cent in women.

$R$ in $V_{5}$ The amplitude of $R$ in $V_{5}$ significantly increases with systolic pressure in both sexes and diminishes with an increase in diastolic pressure but not significantly. The substitution of pulse pressure for systolic and diastolic pressure produced an even more significantly positive coefficient in both

TABLE 5 Average changes in $P R$ interval, $Q R S$ and $T$ axes, and amplitudes of $R$ in aVL, $S$ in $V I, R$ in V5, and $T$ in $V 5$ associated with 10-year increase in age, unit increase in Quetelet's index, $50 \mathrm{mmHg}$ increase in systolic, diastolic, and pulse pressure, and a 50 beats per minute increase in heart rate

\begin{tabular}{|c|c|c|c|c|c|c|c|}
\hline $\begin{array}{l}\text { Electro- } \\
\text { cardiographic }\end{array}$ & $\operatorname{Sex}$ & $\begin{array}{l}\text { Io years of } \\
\text { age }\end{array}$ & $\begin{array}{l}\text { I unit of } \\
\text { Quetelet's } \\
\text { index }\end{array}$ & $\begin{array}{l}50 \mathrm{mmHg} \\
\text { increase of } \\
\text { systolic } \\
\text { pressure }\end{array}$ & $\begin{array}{l}50 \mathrm{mmHg} \\
\text { increase of } \\
\text { diastolic } \\
\text { pressure }\end{array}$ & $\begin{array}{l}50 \mathrm{mmHg} \\
\text { increase of } \\
\text { pulse pressure }\end{array}$ & $\begin{array}{l}50 \text { beats } / \mathrm{min} \\
\text { increase of } \\
\text { heart rate }\end{array}$ \\
\hline PR interval (sec) & $\begin{array}{l}\mathrm{M} \\
\mathrm{F}\end{array}$ & -0.004 & - & - & - & -0.01 & -0.014 \\
\hline QRS axis $\left(^{\circ}\right)$ & $\begin{array}{l}\mathrm{M} \\
\mathrm{F}\end{array}$ & $\begin{array}{l}-7 \cdot 3 \\
-5 \cdot 4\end{array}$ & $\begin{array}{r}-15 \cdot 3 \\
-8 \cdot 1\end{array}$ & $\begin{array}{l}-6 \cdot 7 \\
-5 \cdot 7\end{array}$ & $\begin{array}{l}- \\
-20.7\end{array}$ & - & $\begin{array}{l}-0.014 \\
-\end{array}$ \\
\hline$T$ axis $\left(^{\circ}\right)$ & $\begin{array}{l}\mathrm{M} \\
\mathrm{F}\end{array}$ & -4.0 & $\begin{array}{r}-2 I \cdot 9 \\
-7 \cdot 3\end{array}$ & $\begin{array}{l}-8 \cdot 5 \\
-5.9\end{array}$ & - & $\begin{array}{r}-13.9 \\
-8.9\end{array}$ & +12.9 \\
\hline $\mathbf{R}$ in aVL (mm) & $\begin{array}{l}\mathrm{M} \\
\mathrm{F}\end{array}$ & $\begin{array}{l}+0.5 \\
+0.6\end{array}$ & $\begin{array}{l}+3 \cdot I \\
+I \cdot 6\end{array}$ & $\begin{array}{l}+I \cdot 6 \\
+I \cdot 6\end{array}$ & - & $\begin{array}{l}+I \cdot 7 \\
+I \cdot 5\end{array}$ & - \\
\hline$S$ in $V_{I}(\mathrm{~mm})$ & $\begin{array}{l}\mathrm{M} \\
\mathrm{F}\end{array}$ & $\begin{array}{l}-0.8 \\
-\end{array}$ & - & $\begin{array}{l}+4.2 \\
+3.5\end{array}$ & $-2 \cdot 8$ & $\begin{array}{l}+5.9 \\
+5.4\end{array}$ & - \\
\hline $\mathbf{R}$ in $\mathrm{V}_{5}(\mathrm{~mm})$ & $\begin{array}{l}\mathrm{M} \\
\mathrm{F}\end{array}$ & - & $-\mathbf{I} \cdot 0$ & $\begin{array}{l}+3.7 \\
+3.7\end{array}$ & - & $\begin{array}{l}+4 \cdot 7 \\
+5 \cdot 3\end{array}$ & $\begin{array}{l}-3 \cdot 3 \\
-4 \cdot 0\end{array}$ \\
\hline $\mathrm{T}$ in $\mathrm{V}_{5}(\mathrm{~mm})$ & $\begin{array}{l}\mathbf{M} \\
\mathbf{F}\end{array}$ & -0.2 & $\begin{array}{l}-1 \cdot 3 \\
-0.3\end{array}$ & $\begin{array}{l}-1 \cdot 2 \\
-0.6\end{array}$ & - & $\begin{array}{l}-1.5 \\
-0.7\end{array}$ & $\begin{array}{l}-2 \cdot 2 \\
-I \cdot I\end{array}$ \\
\hline
\end{tabular}


TABLE 6 Standardized coefficients ${ }^{\star}$ relating age, Quetelet's index, pulse pressure, and heart rate with certain electrocardiographic measurements, Lawrence Tavern, famaica

\begin{tabular}{|c|c|c|c|c|c|}
\hline $\begin{array}{l}\text { Electrocardiographic } \\
\text { characteristic }\end{array}$ & Sex & Age & Quetelet's index & Pulse pressure & Heart rate \\
\hline \multirow[t]{2}{*}{ PR interval } & $\mathbf{M}$ & -0.008 & 0.019 & -0.117 & -0.132 \\
\hline & $\mathrm{F}$ & -0.137 & 0.070 & 0.009 & -0.189 \\
\hline \multirow[t]{2}{*}{ QRS axis } & $\mathbf{M}$ & -0.207 & -0.180 & $-0.04 I$ & -0.004 \\
\hline & $\mathbf{F}$ & -0.206 & -0.227 & -0.022 & -0.076 \\
\hline \multirow[t]{2}{*}{$T$ axis } & $\mathbf{M}$ & -0.019 & -0.253 & -0.142 & 0.107 \\
\hline & $\mathrm{F}$ & 0.126 & -0.182 & -0.127 & 0.026 \\
\hline \multirow[t]{2}{*}{$\mathbf{R}$ in aVL } & $\mathbf{M}$ & 0.149 & 0.338 & 0.158 & -0.025 \\
\hline & $\mathrm{F}$ & 0.179 & 0.317 & 0.165 & 0.037 \\
\hline \multirow[t]{2}{*}{$S$ in $V_{I}$} & $\mathrm{M}$ & -0.093 & 0.044 & 0.286 & 0.029 \\
\hline & $\mathrm{F}$ & 0.001 & -0.002 & 0.388 & -0.064 \\
\hline \multirow[t]{2}{*}{$\mathrm{R}$ in $\mathrm{V}_{5}$} & $\mathbf{M}$ & -0.036 & 0.052 & 0.169 & -0.088 \\
\hline & $\mathrm{F}$ & 0.189 & -0.077 & 0.289 & -0.169 \\
\hline \multirow[t]{2}{*}{$T$ in $V_{5}$} & $\mathbf{M}$ & -0.093 & -0.165 & -0.158 & -0.225 \\
\hline & $\mathrm{F}$ & 0.079 & -0.124 & -0.152 & -0.196 \\
\hline
\end{tabular}

$M=$ Men 35 to 64 years, $n=518 . \quad F=$ Women 35 to 64 years, $n=533$.

Coefficients in italics are for relations statistically significant at 5 per cent level.

* I SD unit change in independent variable is associated with change in dependant variable of a size represented (in SD units) by the standardized coefficient.

men and women. In both sexes low heart rates are associated with higher amplitudes of $R$ in $V_{5}$. In women, but not in men, $R$ in $V_{5}$ increases with age and, in contradistinction to $\mathrm{R}$ in aVL, decreases with increases in body build. It is of interest that the 5 variables account for 22 per cent of the variation of $\mathrm{R}$ in $\mathrm{V}_{5}$ in women and only 4 per cent in men.

$T$ in $V_{5}$ Increases in body build, systolic pressure (or pulse pressure), and heart rate are significantly associated with a decrease in the amplitude of $T$ in $\mathrm{V}_{5}$ in both sexes. Age has no significant influence in men, but $\mathrm{T}$ in $\mathrm{V}_{5}$ increases with age in women if other factors are held constant. Fourteen per cent of its variation in men, and 9 per cent in women, can be explained by the combined influence of the 5 variables considered.

The changes expected in these electrocardiographic characteristics for a given change in age, body build, systolic pressure, diastolic pressure, pulse pressure, and heart rate are shown in Table 5. Only those values associated with significant regression coefficients are included. In this analysis the changes expected with a ro-year increase in age, with unit increase in Quetelet's index, and with an increase of heart rate of 50 beats a minute are those that could occur if all other variables were held constant and therefore are a measure of the independent influences of these three factors. As systolic and diastolic pressures are positively and highly correlated some influence of each will transfer to the other when they are considered separately, but the sharing of effects when they are considered together conceals the real influence of blood pressure. We show in Table 5 the expected changes associated with a 50 $\mathrm{mm}$ increase in systolic pressure, ignoring diastolic and additional changes expected from diastolic pressure after allowing for systolic influences. Clearly some caution is necessary in interpreting these changes. The electrocardiographic changes associated with pulse pressure shown in Table 5 are those calculated from regression equations including only the four characteristics, age, body build, pulse pressure, and heart rate.

Age significantly influences more electrocardiographic characteristics in women than in men in this population and, as is the case for body build also, its main influence appears to be on the QRS axis. Body build influences both $Q R S$ and $T$ axis to a greater extent in men than in women. Similarly systolic pressure has a greater influence on electrocardiographic measurements in men than in women, whereas diastolic pressure, after allowing for systolic, only significantly influences electrocardiographic measurements in women. The significant influences of pulse pressure are largely restricted to $T$ axis and wave amplitudes and those of heart rate are largely restricted to $P R$ interval and the amplitudes of $R$ and $T$ in lateral leads.

Standardized coefficients indicating the change in electrocardiographic characteristics (measured in SD units) associated with I SD unit change in age, body build, pulse pressure, and heart rate (Table 6) allow an evaluation of the relative importance of these four variables in influencing electrocardio- 
TABLE 7 Means and standard deviations of certain electrocardiographic characteristics in two Caribbean adult populations of African origin and two U.S. adult populations of European origin, according to age and sex

\begin{tabular}{|c|c|c|c|c|c|c|c|c|c|c|c|}
\hline & & \multicolumn{4}{|c|}{ Caribbean 35-44 years } & \multicolumn{4}{|c|}{ U.S.A. 30-39 years } & \multirow{2}{*}{\multicolumn{2}{|c|}{$\frac{\text { Caribbean } 45-54}{\text { Famaica }}$}} \\
\hline & & \multicolumn{2}{|c|}{ Famaica* } & \multicolumn{2}{|c|}{ Guyanas } & \multicolumn{2}{|c|}{ Tecumseh $†$} & \multicolumn{2}{|c|}{ Minnesota $\ddagger$} & & \\
\hline & & $\begin{array}{l}M \\
(I 68)\end{array}$ & $\begin{array}{l}F \\
(I 8 I)\end{array}$ & $\begin{array}{l}M \\
(78)\end{array}$ & $\begin{array}{l}F \\
(I I 8)\end{array}$ & $\begin{array}{l}M \\
(679)\end{array}$ & $\begin{array}{l}F \\
(702)\end{array}$ & $\begin{array}{l}M \\
(I I O)\end{array}$ & $\begin{array}{l}F \\
(65)\end{array}$ & $\begin{array}{l}M \\
(I 80)\end{array}$ & $\begin{array}{l}F \\
(I 8 I)\end{array}$ \\
\hline \multirow[t]{2}{*}{ PR interval } & M & 0.169 & 0.165 & & & 0.167 & $0.16 I$ & 0.165 & 0.156 & 0.171 & 0.162 \\
\hline & SD & 0.028 & 0.024 & & & 0.024 & 0.023 & 0.016 & 0.021 & 0.025 & 0.022 \\
\hline \multirow[t]{2}{*}{ QRS axis } & M & $5 \mathrm{I} \cdot 2$ & 38.9 & $42 \cdot I$ & $32 \cdot 0$ & & & $51 \cdot 7$ & $53 \cdot 8$ & $38 \cdot 9$ & $36 \cdot 9$ \\
\hline & SD & $26 \cdot 1$ & $24 \cdot 1$ & $3 I \cdot 3$ & $29 \cdot 3$ & & & $29 \cdot I$ & $24 \cdot 8$ & $33 \cdot 2$ & 23.9 \\
\hline \multirow[t]{2}{*}{$\mathrm{T}$ axis } & M & 35.5 & $30 \cdot 3$ & & & & & $43 \cdot I$ & $35^{\circ} 0$ & $36 \cdot 9$ & $29 \cdot I$ \\
\hline & SD & $24 \cdot 6$ & $18 \cdot 1$ & & & & & 18.3 & 20.7 & $23 \cdot 5$ & $29 \cdot 9$ \\
\hline \multirow[t]{2}{*}{ R aVL } & $\mathbf{M}$ & $3 \cdot 1$ & $4 \cdot 3$ & 3.9 & $4 \cdot 4$ & $3 \cdot 4$ & $2 \cdot 9$ & $2 \cdot 4$ & $2 \cdot 3$ & 4.0 & $4 \cdot 7$ \\
\hline & SD & $2 \cdot 7$ & $3 \cdot 2$ & $3 \cdot 8$ & $3 \cdot 3$ & $2 \cdot 5$ & $2 \cdot 2$ & $2 \cdot 2$ & $2 \cdot 5$ & 3.5 & $3 \cdot 1$ \\
\hline \multirow[t]{2}{*}{$S V_{I}$} & M & 12.5 & $10 \cdot 6$ & $12 \cdot 4$ & $9 \cdot 4$ & 10.3 & 9.I & $9 \cdot 2$ & $7 \cdot 6$ & I I 4 & II $\cdot 3$ \\
\hline & SD & $5 \cdot 3$ & $4 \cdot 6$ & $5 \cdot 1$ & $4 \cdot 3$ & $4 \cdot 5$ & 3.9 & $3 \cdot 7$ & $3 \cdot 6$ & 4.6 & 5.5 \\
\hline \multirow[t]{2}{*}{$\mathrm{R} \mathrm{V}_{5}$} & 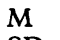 & $2 I \cdot 2$ & 15.3 & $20 \cdot 2$ & 13.9 & 15.4 & $11 \cdot 7$ & $14 \cdot 3$ & 10.8 & $2 I \cdot I$ & $17 \cdot 4$ \\
\hline & $S D$ & 8.5 & 5.6 & 6.5 & $4 \cdot 7$ & $4 \cdot 8$ & $3 \cdot 6$ & $4 \cdot 2$ & $4 \cdot 3$ & $8 \cdot 1$ & 5.9 \\
\hline \multirow[t]{2}{*}{$\mathrm{T} \mathrm{V}_{5}$} & M & $4 \cdot 7$ & $2 \cdot 7$ & $3 \cdot 2$ & $1 \cdot 8$ & & & $3 \cdot 7$ & $2 \cdot 9$ & $4 \cdot 7$ & $2 \cdot 6$ \\
\hline & SD & $2 \cdot 7$ & $1 \cdot 3$ & $2 \cdot I$ & $I \cdot 3$ & & & $1 \cdot 5$ & $I \cdot I$ & $2 \cdot 9$ & $1 \cdot 9$ \\
\hline
\end{tabular}

* Present series † Ostrander et al. (1965). ‡ Simonson (196I). \Ashcroft et al. (1970).

graphic measurements. For example, age and Quetelet's index independently account for approximately equal changes in QRS axis whereas pulse pressure and heart rate have negligible effects; one SD unit in body build and pulse pressure would account for two-thirds of an SD unit change of $R$ in aVL in both sexes. Only pulse pressure of the four variables significantly influences the amplitude of $R$ in $V_{5}$ in men, whereas all but body build do in women. Clearly $\mathrm{R}$ in $\mathrm{V}_{5}$ in men is largely determined by factors other than those included in this analysis.

\section{Comparison with other surveys}

A similar survey of a neighbouring Caribbean population with which the Jamaican findings can be compared is that of a Guyanese community reported by Ashcroft et al. (1970). A close similarity is found between the electrocardiogram measurements of Guyanese of African origin and Jamaicans of African origin (Table 7). The somewhat greater values of $R$ in aVL in Guyanese probably reflect the differences in QRS axis deviation which accompanied their heavier body build (as assessed by Quetelet's index) and their higher systolic and diastolic pressures which were present in both sexes and each age group. The amplitudes of $S$ in $V_{I}$ and $R$ and $T$ in V5 are larger in Jamaicans than Guyanese but the differences are small.
Both of these Caribbean surveys show differences from the measurements made in a survey of the general population of largely white Americans in Tecumseh, U.S.A., reported by Ostrander et al. (1965), and from the normal values of clinically screened American working populations given by Simonson (I96I), both of which are included in Table 7. Similar differences were reported by Ash-

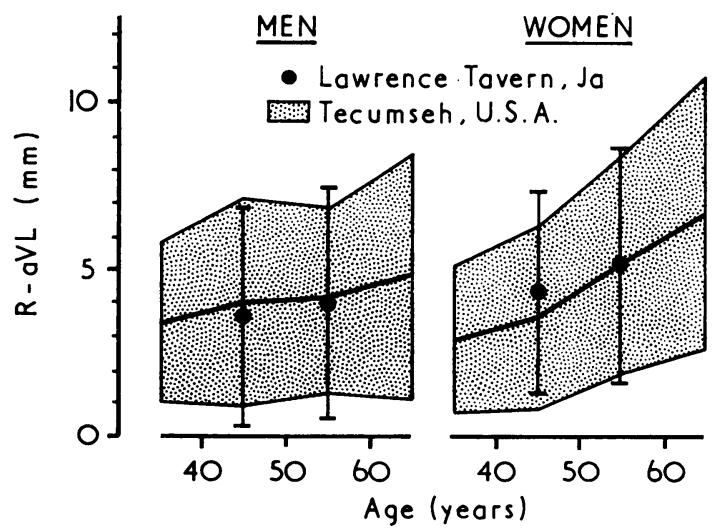

FIG. I Means ( \pm I $S D$ ) of the amplitudes of $R$ in $a V L$, in electrocardiograms of adults, in Lawrence Tavern, Famaica and Tecumseh, U.S.A. (Ostrander et al., I965), by age and sex. 


\begin{tabular}{|c|c|c|c|c|c|}
\hline \multirow{2}{*}{\multicolumn{2}{|c|}{$\frac{\text { years }}{\text { Guyana }}$}} & \multicolumn{4}{|c|}{ U.S.A. $30-39$ years $40-59$ years } \\
\hline & & \multicolumn{2}{|c|}{ Tecumseh } & \multicolumn{2}{|c|}{ Minnesota } \\
\hline $\begin{array}{l}M \\
(87)\end{array}$ & $\begin{array}{l}F \\
(I 24)\end{array}$ & $\begin{array}{l}M \\
(467)\end{array}$ & $\begin{array}{l}F \\
(474)\end{array}$ & $\begin{array}{l}M \\
(424)\end{array}$ & $\begin{array}{l}F \\
(I 42)\end{array}$ \\
\hline & & $\begin{array}{l}0.167 \\
0.025\end{array}$ & $\begin{array}{l}0.162 \\
0.022\end{array}$ & $\begin{array}{l}0.164 \\
0.018\end{array}$ & $\begin{array}{l}0.156 \\
0.021\end{array}$ \\
\hline $\begin{array}{l}30 \cdot 7 \\
34 \cdot 3\end{array}$ & $\begin{array}{l}27 \cdot 0 \\
26 \cdot 2\end{array}$ & & & $\begin{array}{l}37 \cdot 2 \\
32 \cdot 0 \\
37 \cdot 7 \\
20 \cdot 2\end{array}$ & $\begin{array}{l}41 \cdot 9 \\
25 \cdot 8 \\
36 \cdot 9 \\
18 \cdot 7\end{array}$ \\
\hline $\begin{array}{l}3.9 \\
3.4\end{array}$ & $\begin{array}{l}5 \cdot 2 \\
3 \cdot 9\end{array}$ & $\begin{array}{l}4 \cdot 0 \\
3 \cdot 1\end{array}$ & $\begin{array}{l}3 \cdot 6 \\
2 \cdot 8\end{array}$ & $\begin{array}{l}3.4 \\
2 \cdot 5\end{array}$ & $\begin{array}{l}3 \cdot 3 \\
2 \cdot 5\end{array}$ \\
\hline $11 \cdot 7$ & 10.4 & $9 \cdot 4$ & $9 \cdot I$ & $8 \cdot 6$ & $7 \cdot 2$ \\
\hline $6 \cdot 0$ & $4 \cdot 4$ & $4 \cdot 3$ & 3.9 & $3 \cdot 6$ & $3 \cdot 2$ \\
\hline $20 \cdot 2$ & 15.3 & 14.5 & II 6 & $14 \cdot I$ & II 6 \\
\hline $\begin{array}{l}7 \cdot 3 \\
3 \cdot 4 \\
2 \cdot 3\end{array}$ & $\begin{array}{l}4.9 \\
I \cdot 7 \\
I .5\end{array}$ & $5 \cdot 0$ & $4 \cdot 0$ & $\begin{array}{l}4.8 \\
3.9 \\
1.7\end{array}$ & $\begin{array}{l}3 \cdot 9 \\
2 \cdot 9 \\
1 \cdot 2\end{array}$ \\
\hline
\end{tabular}

croft and his colleagues in comparing the electrocardiographic characteristics of Guyanese of African and Indian extraction.

The similarity of the means (and standard deviations) of the amplitudes of $\mathrm{R}$ in aVL in Jamaicans and Americans from Tecumseh (Fig. I) contrasts considerably with the differences in the values of $\mathrm{R}$ in V5 (Fig. 2). This is true of both sexes. Comparison with the Simonson values reveals similar differences. Simonson gives values for $R$ in $V_{5}$ which average approximately two-thirds of those of rural Jamaicans. The amplitudes of the $T$ wave in $\mathrm{V}_{5}$ in women, however, have smaller mean values (but larger standard deviations) in Jamaica and Guyana.

Mean values (and standard deviations) of QRS axis are similar in Jamaican men to the normal values quoted by Simonson but show greater deviation to the left in Jamaican women. The axis of $T$ in both sexes is also somewhat to the left of the Simonson norms. Reports concerning the electrocardiograms of Africans in Africa are conflicting but no adequate population studies have been published of their electrocardiographic characteristics in either Africa or the U.S.A. Brink (195I) noted high amplitude complexes in almost half the Bantu men he studied in South Africa. Grusin (1954) from South Africa, Somers and Rankin (1962) from Uganda, and Seriki and Smith (1966) from Nigeria have also

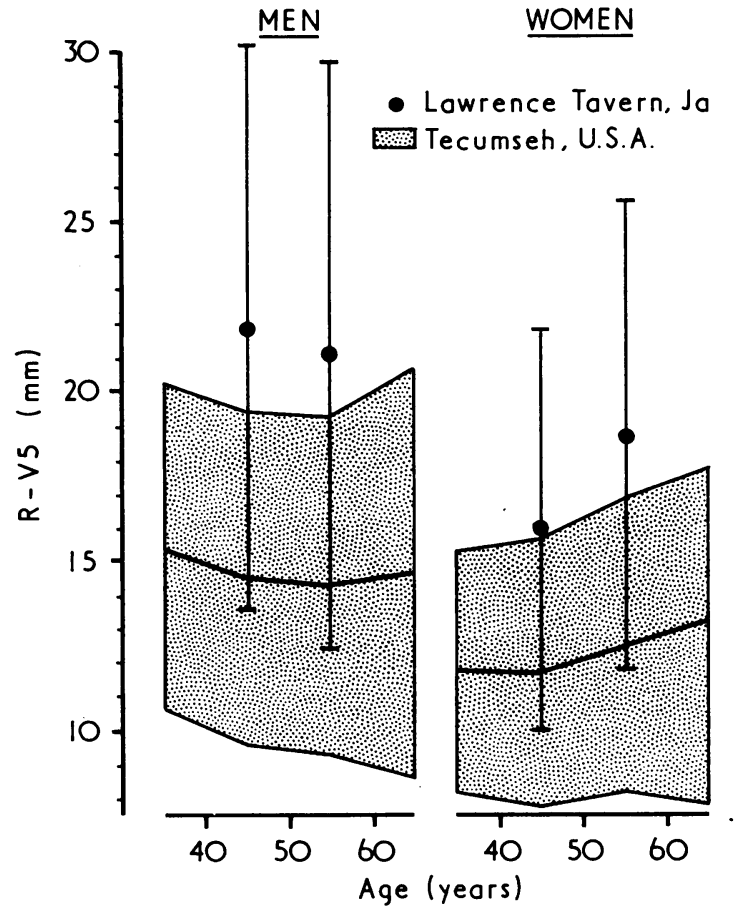

FIG. 2 Means ( \pm I $S D$ ) of the amplitudes of $R$ in $V_{5}$ in electrocardiograms of adults in Lawrence Tavern, Jamaica, and Tecumseh, U.S.A. (Ostrander et al., 1965).

reported similar findings in normotensive healthy young Africans. On the other hand, Turner (1959) reported unusually small amplitudes in normal young adult Kikuyu males, and similar findings have been observed in the Gambia (D. Howells, 1966, personal communication).

\section{Discussion}

This analysis had two major objectives. One aim was to record in some detail the electrocardiographic measurements of a representative Jamaican community and to compare them with those of other populations. This has shown close similarities to the observations made on another Caribbean population of African origin and some features very different from those reported for Caucasian populations, particularly with respect to the wave amplitudes over the left ventricle. Previous analysis using the revised Minnesota code criteria of Rose and Blackburn (1966) had shown that the outstanding electrocardiographic characteristic of this rural Jamaican population, when compared with American and European populations, was a high rate of tall $\mathbf{R}$ waves in left ventricular leads and a correspon- 
ding high rate of ST and $\mathrm{T}$ wave abnormalities (Miall et al., 1972a).

The second objective was to assess the roles of age and certain physical measurements in influencing electrocardiographic characteristics and in particular to assess the part played by raised arterial pressure in determining the amplitudes of QRS complexes and $T$ waves in the praecordial leads. The analysis has shown that high systolic pressure in particular is associated with increased amplitudes of $S$ in VI and R in V5, and with diminished amplitudes of $\mathrm{T}$ in $\mathrm{V}_{5}$ in both sexes. Increased diastolic pressure, holding systolic constant is, however, associated with decreased amplitudes of $S$ in $V_{I}$ and $R$ in V5, which suggested that pulse pressure might be the crucial variable concerned. Subsequent regression analyses using pulse pressure as a variable, to replace both systolic and diastolic pressure, did not confirm this; the regression coefficients of amplitudes on pulse pressure were no more highly significant, in general, than those obtained previously with systolic and diastolic pressure included in the equations.

Though high systolic pressure plays an important role in influencing voltages in the praecordial leads it plays a minor role in determining the amplitude of $\mathrm{R}$ in aVL. Conversely, body build, which is highly significantly associated with QRS axis and thus with $\mathrm{R}$ in aVL, plays little part in determining the amplitudes of $R$ and $S$ in praecordial leads, though it highly significantly influences the amplitude of $\mathrm{T}$ in $\mathrm{V}_{5}$.

It is chastening to note how little of the variation of most of the electrocardiographic measurements is explained by age, body build, blood pressure, and heart rate. Technical factors probably play a major role in determining amplitudes, particularly the positioning of chest electrodes, electrical distortion, the anatomical position of the heart, the chest configuration, and the state of the respiratory cycle. The considerable sex differences in amplitudes of complexes over the left ventricle are partly determined by breast tissue and differences in chest configuration as well as by the relatively small heart size of women. These and other variables not included in the analysis may be of major importance. In this respect it is of interest that in women 22 per cent of the variation of $R$ in $V_{5}$ was explained by the 5 independent variables considered, whereas in men they only accounted for 4 per cent. Neither age, body build, pulse pressure, nor heart rate significantly influenced the amplitude of $R$ in $V_{5}$ in men whereas all four did in women. The heavy physical demand of hand cultivation of precipitously steep hillsides is likely to be an important interfering factor in men.

The approximately equal mean amplitudes of $\mathbf{R}$ in $V_{5}$ in the three age groups of men may be due to a balance of factors operating in different directions. For example the expected increase in amplitude associated with the higher prevalence of hypertension in older subjects may be balanced by diminished amplitudes as the physical demands of heavy manual work lessen. A selective mortality of those with the higher amplitudes would also contribute to the age relations found. In women, where hypertension is likely to be the most common cause of ventricular hypertrophy, it is reasonable to attribute to it much of the increase in amplitudes of $R$ in V5.

In some respects this analysis produces findings which do not accord with those of Simonson (196I), particularly with respect to the influence of arterial pressure. For example Simonson, analysing data for men aged 40 to 59 and within this age group ignoring age, describes a progressive shift of $Q R S$ axis to the left with increasing systolic pressure and no change in $T$ axis, whereas in our results the shift of QRS axis in men is largely attributable to age, not to systolic blood pressure which does however significantly influence the $T$ axis (Table 4 ). Diastolic pressure, according to Simonson, does not affect QRS axis but does determine $T$ axis shift. In our analysis of data for men, systolic but not diastolic pressure determines the $\mathrm{T}$ axis (Table 4). Simonson concludes from his analysis 'that systolic and diastolic pressures affect the ECG differently, and that diastolic pressure appears to be the more important'; he is referring to findings in men. Our conclusion would be that in Jamaicans systolic pressure is much the more important determinant of changes in those electrocardiographic characteristics we have examined, when the influences of systolic and diastolic pressure are examined simultaneously. It is likely that these differences between Simonson's findings and ours result from differences in selection and methods of analysis rather than from ethnic factors.

The influence of body build on the electrocardiographic characteristics of Jamaicans, on the other hand, is similar to that described by Simonson for Americans. Greater relative weight causes a shift of QRS and T axes to the left, has little influence on praecordial QRS amplitudes, and significantly diminishes $T$ wave amplitudes.

Elsewhere we have shown that the electrocardiographic abnormalities found in this rural community in Jamaica, when analysed semiquantitatively according to the criteria of the Minnesota code, reveal an unexpectedly high prevalence of myocardial disorders and that symptoms of a mild type of effort pain and electrocardiographic signs compatible with myocardial ischaemia have independent prognostic significance in addition to that due to hypertension 
(Miall et al., 1972a, b). In men both the rate of progression and the incidence of 'ischaemic' electrocardiographic abnormalities was increased in those with the voltage criteria of left ventricular hypertrophy, whether they were hypertensive or normotensive, but much of the disease detected was not attributable to hypertension (Miall et al., 1972c).

This paper does not attempt to relate electrocardiographic abnormalities with other evidence of myocardial disorder. The prevalence of ventricular hypertrophy in this population, and the relation between electrocardiographic evidence of left heart involvement and cardiovascular symptoms and signs are also discussed elsewhere (Ruiz et al., 1973). The prognostic significance of left ventricular hypertrophy has been described from the Framingham study (Kannel, Gordon, and Offutt, 1969; Kannel et al., 1970), and merits further study among populations of African ancestry.

The frequency of left ventricular hypertrophy, as judged by the electrocardiogram, is unexpectedly common in rural Jamaica. Stuart and Hayes (1963) described from Jamaica a type of cardiac disorder of unknown cause of which the predominant signs are ventricular hypertrophy and unexplained cardiac failure. Cardiomyopathies are largely diagnosed by exclusion, and their prevalence is thus difficult to measure. Gross unexplained cardiomegaly, though more common in Jamaica than in the U.K., for example, is a relatively rare condition in the general population. It is possible that some of the unexplained myocardial disorder seen in this population represents the iceberg for which the tip is represented by terminal cases of gross disorder as described from hospital populations. The further follow-up of this population may reveal the prognostic significance of ventricular hypertrophy which, among men particularly, is inadequately accounted for by hypertension and may be related to occupational factors.

We gratefully acknowledge the help of our colleagues in the MRC Epidemiology Unit (Jamaica) and in particular Dr. Charles Florey and Mrs. P. Desai for computing assistance, Mrs. V. Jutsum for Minnesota Code readings, and the contribution made by the Unit's field research team. We would especially thank the people of Lawrence Tavern for their continuing cooperation in this study.

\section{References}

American Heart Association (1967). Committee on Electrocardiography. Recommendations for standardization of leads and of specifications for instruments in electrocardiography and vectorcardiography. Circulation, 35, 583.

Ashcroft, M. T., Beadnell, H. M. S. G., Bell, R., and Miller, G. J. (1970). Characteristics relevant to cardiovascular disease among adults of African and Indian origin in Guyana. Bulletin of the World Health Organization, 42, 205 .
Brink, A. J. (195I). An investigation of factors influencing repolarization in the human heart. South African fournal of Clinical Science, 2, 288.

Estes, E. H. (1966). Electrocardiography and vectorcardiography. Chapter 6, in The Heart, Ed. by J. W. Hurst and R. B. Vogue. McGraw-Hill Book Co., New York.

Grusin, H. (1954). Peculiarities of the African's electrocardiogram and the changes observed in serial studies. Circulation, 9, 860.

Kannel, W. B., Gordon, T., Castelli, W. P., and Margolis, J. R. (1970). Electrocardiographic left ventricular hypertrophy and risk of coronary heart disease. Annals of Internal Medicine, 72, 813.

Kannel, W. B., Gordon, T., and Offutt, D. (1969). Left ventricular hypertrophy by electrocardiogram. Annals of Internal Medicine, 71, 89.

Miall, W. E., del Campo, E., Fodor, J., Nava Rhode, J. R., Ruiz, L., Standard, K. L., and Swan, A. V. (I972a). A longitudinal study of heart disease in a Jamaican rural population. (I) Prevalence, with special reference to electrocardiographic findings. Bulletin of the World Health Organization, 46, 429.

Miall, W. E., del Campo, E., Fodor, J., Nava Rhode, J. R., Ruiz, L., Standard, K. L., and Swan, A. V. (1972b). A longitudinal study of heart disease in a Jamaican rural population. (2) Factors influencing mortality. Bulletin of the World Health Organization, 46, 685.

Miall, W. E., del Campo, E., Fodor, J., Nava Rhode, J. R., Ruiz, L., and Standard, K. L. (1972c). A longitudinal study of heart disease in a Jamaican rural population. (3) Factors influencing changes in serial electrocardiograms. Bulletin of the World Health Organization, 46, 695.

Morris, J. J., Estes, E. H., Whalen, R. E., Thompson, H. K., and McIntosh, H. D. (1964). P-wave analysis in valvular heart disease. Circulation, 29, 242.

Ostrander, L. D., Brandt, R. L., Kjelsberg, M. O., and Epstein, F. H. (1965). Electrocardiographic findings among the adult population of a total natural community, Tecumseh, Michigan. Circulation, 31, 888.

Rose, G. A., and Blackburn, H. (1966). Cardiovascular population studies: Methods. World Health Organization, Geneva.

Ruiz, L., Miall, W. E., and Swan, A. V. (1973). Electrocardiographic indices of left heart involvement in adults in a Jamaican rural population. To be published.

Seriki, O., and Smith, A. J. (1966). The electrocardiogram of young Nigerians. American Heart fournal, 72, 153.

Simonson, E. (196I). Differentiation Between Normal and Abnormal in Electrocardiography. C. V. Mosby Company, St. Louis.

Sokolow, M., and Lyon, T. P. (1949). The ventricular complex in left ventricular hypertrophy as obtained by unipolar precordial and limb leads. American Heart fournal, 37, $16 \mathrm{r}$.

Somers, K., and Rankin, A. M. (1962). The electrocardiogram in healthy East African (Bantu and Nilotic) men. British Heart fournal, 24, 542.

Stuart, K. L., and Hayes, J. A. (1963). A cardiac disorder of unknown aetiology in Jamaica. Quarterly fournal of Medicine, N.S. 32, 99.

Turner, P. P. (1959). The electrocardiogram in fifty normal young adult Kikuyu males. East African Medical fournal, 36,555 .

Wright, B. M., and Dore, C. F. (1970). A random-zero sphygmomanometer. Lancet, $\mathrm{I}, 337$.

Requests for reprints to Dr. W. E. Miall, M.R.C./ D.H.S.S. Epidemiology and Medical Care Unit, Northwick Park Hospital, Watford Road, Harrow, Middlesex HAI 3 UJ. 